\title{
Cocos nucifera Oil Decreases Edema and Mechanical Hypernociception Induced by Bothrops jararacussu Venom in Mice
}

\section{두(ㅇ) (ㅇ)}

\author{
Authors \\ Álvaro S. Lisboa-Neto', Anita E.A.S. Ribeiro², Eliane F. Feitosa³ , Carlos W.S. Wanderley4, Ana Paula de Oliveira², \\ Jackson R.G.S. Almeida², Raimundo C. Palheta-Junior ${ }^{1,2,3}$
}

Affiliations

1 Pós-Graduação em Ciências Veterinárias no Semiárido, Universidade Federal do Vale do São Francisco, Petrolina, Pernambuco, Brazil

2 Pós-Graduação em Recursos Naturais do Semiárido, Universidade Federal do Vale do São Francisco, Petrolina, Pernambuco, Brazil

3 Colegiado de Medicina Veterinária, Universidade Federal do Vale do São Francisco, Petrolina, Pernambuco, Brazil

4 Departamento de Fisiologia e Farmacologia, Universidade Federal do Ceará, Fortaleza, Ceará, Brazil

Key words

Cocos nucifera, Arecaceae, inflammation, Bothrops jararacussu, edema, pain

received 04.10 .2016

revised $\quad 08.02 .2017$

accepted 28.02.2017

Bibliography

DOI http://dx.doi.org/10.1055/s-0043-105273

Planta Med Int Open 2017; 4: e17-e23

(c) Georg Thieme Verlag KG Stuttgart · New York

ISSN 2509-9264

Correspondence

Raimundo Campos Palheta-Junior

Colegiado de Medicina Veterinária

Universidade Federal do Vale do São Francisco

Rod. BR 407, Km 12, Lote 543

Projeto de Irrigação Senador Nilo Coelho

$\mathrm{s} / \mathrm{n}^{\circ}-\mathrm{C} 1$ - CEP 56.300-990
Petrolina, Pernambuco, Brazil

Tel.: +55/87/21 0148 39, Fax: +55/87/21016798

raimundo.palheta@univasf.edu.br

\begin{abstract}
Bothropic venoms cause intense local damage, pain, edema, and myonecrosis. Cocos nucifera is the naturally most widespread fruit plant on Earth, and both the fruit and the plant have been used in folk medicine for the treatment of several inflammatory disorders. We evaluated the anti-inflammatory and analgesic effects of virgin coconut oil that was obtained from $C$. nucifera on paw lesions that were induced by venom from the Bothrops jararacussu snake in mice. Nuclear magnetic resonance spectroscopy was used to determine the chemical profile of virgin coconut oil. The analysis of the main components showed that saturated and unsaturated fatty acids were prominent components of the oil. Virgin coconut oil at doses of 100,200 , and $400 \mathrm{mg}$ reduced local edema that was induced by B. jararacussu venom. The $200-\mathrm{mg}$ dose of virgin coconut oil prevented edema that was induced by histamine, serotonin, and bradykinin. However, virgin coconut oil did not prevent edema that was induced by substance $P$ or prostaglandin $E_{2}$. Virgin coconut oil also reduced peritoneal leukocyte infiltration that was induced by carrageenan and also decreased B. jararacussu venom-induced mechanical hypernociception of the paw. Virgin coconut oil exerted an anti-inflammatory effect on paw injury that was induced by $B$. jararacussu venom in mice, most likely by inhibiting leukocyte migration and reducing the action of the same inflammatory agents. The analgesic activity of virgin coconut oil appears to depend on opioid receptors.
\end{abstract}

\section{Introduction}

Ophidic accidents are a concerning health problem, especially in tropical countries. In Brazil, most such accidents involve snakes of the Bothrops genus, the venom of which induces extensive local damage followed by marked edema, pain, erythema, ecchymosis, tissue necrosis, and extensive hemorrhage through alterations of platelet function [1,2]. Several studies have shown that inflammatory mediators, such as histamine, bradykinin, and prostaglandin, may contribute to the amplification of local damage subsequent to an intraplantar injection of Bothrops venom, and commercial anti-venom does not effectively neutralize the inflammatory response [3-8].

Nonsteroidal anti-inflammatory drugs (NSAIDs) can be used to treat inflammatory processes, including those that are elicited by snakebites [9]. However, the utility of NSAIDs is limited because of their side effects, such as gastric and duodenal ulceration and renal failure that occurs through the inhibition of prostaglandin synthesis [10]. Natural products with less toxic effects have been tested as alternative and complementary treatments for inflammatory responses that are related to ophidic accidents $[11,12]$. 


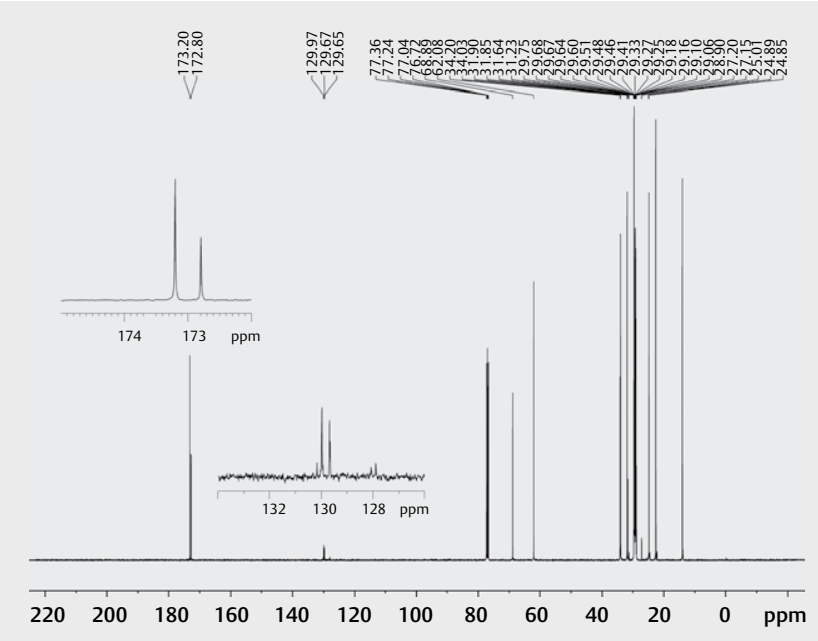

- Fig. $1{ }^{13} \mathrm{C}-\mathrm{NMR}$ spectra of C. nucifera oil $\left(\mathrm{CDCl}_{3}, 100 \mathrm{MHz}\right)$.

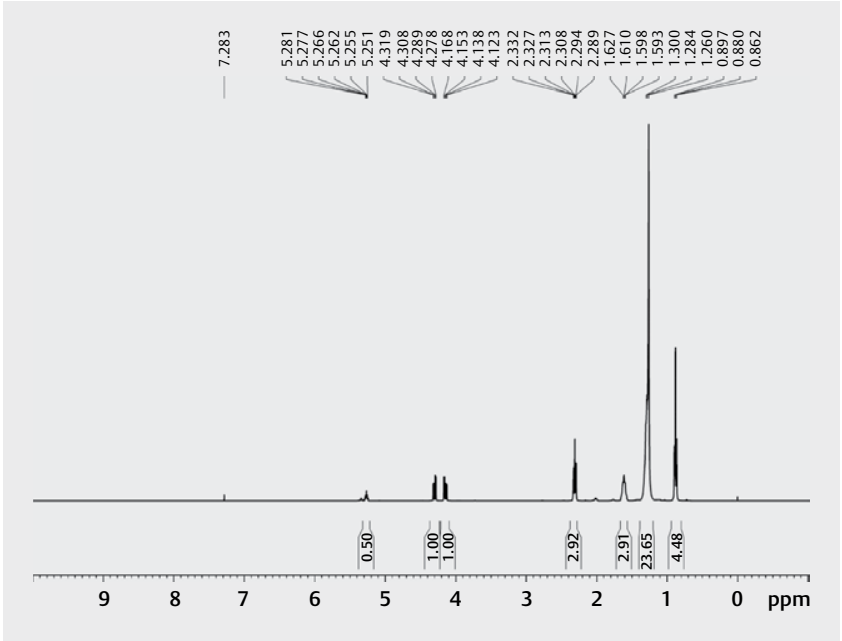

- Fig. $2{ }^{1} \mathrm{H}-\mathrm{NMR}$ spectra of $\mathrm{C}$. nucifera oil $\left(\mathrm{CDCl}_{3}, 400 \mathrm{MHz}\right)$.

Plant extracts have been used in folk medicine to treat or attenuate several inflammatory conditions, including snakebites [12,13]. The aqueous crude extract of husk fiber from Cocos nucifera L. (Arecaceae) is widely used in northeastern Brazilian folk medicine to treat diarrhea and arthritis, and several parts of the fruit and plant have been used by people in different countries for the treatment of several ailments $[14,15]$. The crude extract and virgin coconut oil (VCO) from C. nucifera have been reported to have anti-inflammatory, analgesic, antimicrobial, and antiulcerogenic properties in experimental models in rodents [16-24].

In the present study, we evaluated the possible anti-inflammatory and analgesic effects of VCO (C. nucifera) on paw injury that was induced by Bothrops jararacussu snake venom (BjcuV) and investigated the possible pharmacological mechanisms that underlie the effects of VCO.

\section{Results and Discussion}

The mixtures and composition of saturated and unsaturated fatty acids in the natural oils were identified by ${ }^{13} \mathrm{C}$ - and ${ }^{1} \mathrm{H}$-NMR spec-

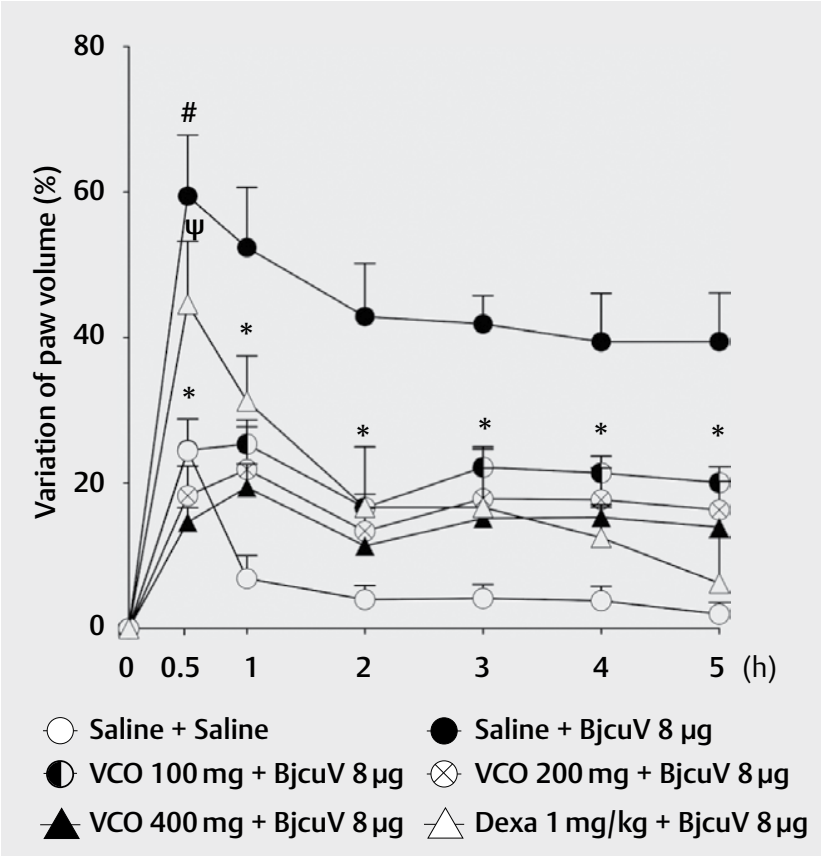

- Fig. 3 Effect of virgin coconut oil on BjcuV-induced paw edema in mice. The animals were orally pretreated with VCO $(100,200$, or $400 \mathrm{mg}), 0.15 \mathrm{M} \mathrm{NaCl}(0.2 \mathrm{ml})$, or dexamethasone (Dexa; $1 \mathrm{mg} / \mathrm{kg}$, i.p.). Each point represents the mean \pm SEM from 5 animals. ${ }^{*} \mathrm{P}<0.05$, significant difference from control group.

tra [25]. The ${ }^{13} \mathrm{C}$-NMR spectral data ( $\bullet$ Fig. 1) indicated the presence of saturated fatty acids in VCO, with signals in the range of 14.00-34.00 ppm. In this region, there were many overlapping signals, and similar chemical shifts were observed for different fatty acids. The presence of unsaturated fatty acids was revealed by signals at $129.65 \mathrm{ppm}\left(\mathrm{C}_{9}\right)$ and $129.67 \mathrm{ppm}\left(\mathrm{C}_{10}\right)$, characteristic of the presence of oleic acid. Signals at 172.8 and $173.2 \mathrm{ppm}$ were assigned to carbonyl groups of fatty acids [25]. The presence of olefinic protons of unsaturated fatty acids was confirmed by signals around $5.2 \mathrm{ppm}$ in the ${ }^{1} \mathrm{H}-\mathrm{NMR}$ spectrum ( $\mathbf{F i g} . \mathbf{2}$ ).

This chemical composition of the VCO that we observed was consistent with the product packaging, in which the main fatty acids were caproic, caprilic, capric, lauric, meristic, palmitic, stearic, oleic, and linoleic acids. Some of these components were identified by gas chromatography of VCO that was collected from Chiang Rai province in Northern Thailand [18]. The presence of unsaturated acids (e.g., palmitic and stearic acids) and monounsaturated fatty acid (oleic acid) influences the membrane permeability of many organelles and suppresses enzyme activity (e. g., phospholipase $A_{2}\left[P L A_{2}\right]$ ), leading to the suppression of inflammatory processes $[18,26]$.

These fatty acids from VCO may attenuate the inflammatory response that is elicited by BjcuV (> Fig. 3). The choice a bothropic venom as a phlogistic agent was based on a previous study that demonstrated that these snake venoms induce paw edema earlier than carrageenan, which has been widely used as a pharmacological agent to induce edema $[2,5,7,27]$. Notably, neither mortality nor lethal toxicity occurred after VCO treatment or the BjcuV injection. 

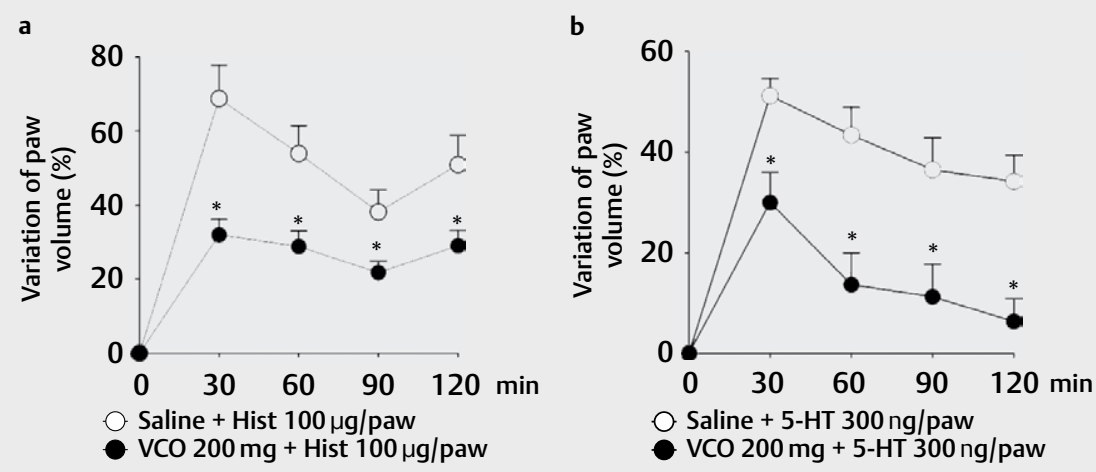

- VCO $200 \mathrm{mg}+$ Hist $100 \mu \mathrm{g} /$ paw

Saline + 5-HT $300 \mathrm{ng} / \mathrm{paw}$

- VCO $200 \mathrm{mg}+5-\mathrm{HT} 300 \mathrm{ng} / \mathrm{paw}$

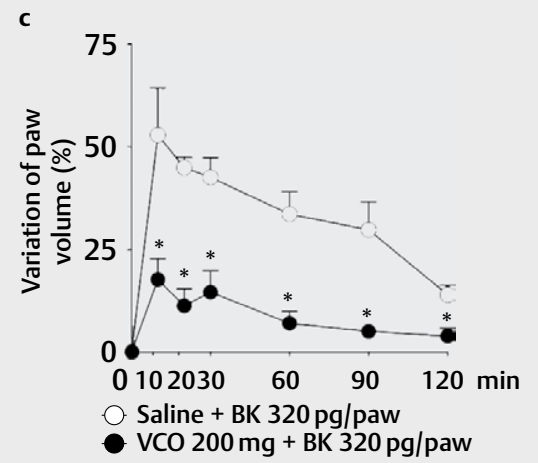

d
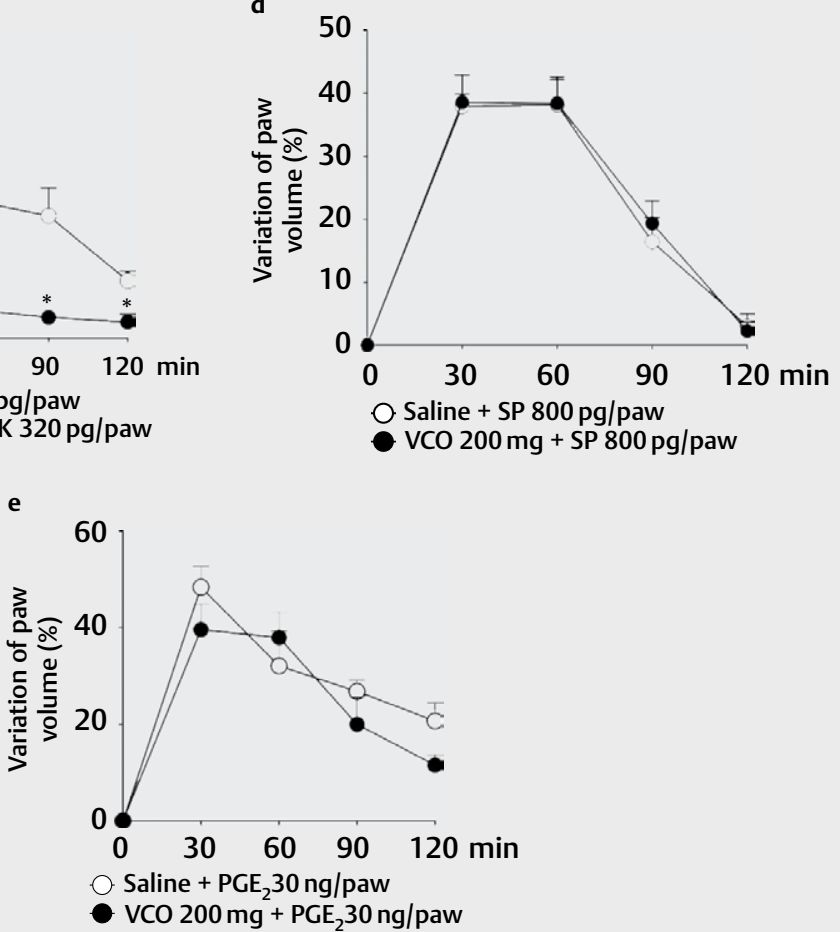

Fig. 4 Effects of virgin coconut oil on paw inflammation induced by different phlogistic agents. Edema was induced by histamine a, serotonin $\mathbf{b}$, bradykinin c, substance $\mathrm{Pd}$, and prostaglandin $\mathrm{E}_{2}\left(\mathrm{PGE}_{2}\right)$ e. The animals were orally pretreated with VCO ( $\left.200 \mathrm{mg}\right)$ or $0.2 \mathrm{ml}$ of $0.15 \mathrm{M} \mathrm{NaCl}$. Each point represents the mean \pm SEM from 5 animals. ${ }^{*} \mathrm{P}<0.05$, significant difference from control group.

Fig. 3 shows significant paw edema 30 min after the BjcuV injection, which was significantly decreased $(p<0.05)$ by 100,200 , and $400 \mathrm{mg}$ VCO. The positive control dexamethasone decreased $(p<0.05)$ paw edema only 60 min after the BjcuV injection. These anti-inflammatory effects of VCO and dexamethasone were sustained for $5 \mathrm{~h}$ post-venom inoculation. The reduction of edema formation by pretreatment with the corticosteroid dexamethasone supports previous findings that the inflammatory response amplifies local tissue damage after bothropic inoculation $[4,7,28]$.

The present results reinforce the potential therapeutic use of coconut products, which have been used as nutraceutical products in folk medicine for the treatment of various metabolic and inflammatory diseases $[14,15]$. The use of $C$. nucifera in folk medicine has been supported by studies of the anti-inflammatory effects of a crude extract of $C$. nucifera in a rat model of carrageenan-induced paw edema $[17,20]$. Similar anti-inflammatory activity of VCO (C. nucifera) has been observed, which may be associated with its polyphenol and fatty acid content $[18,19]$.

The significant suppressive effects of VCO on the first phase of carrageenan-induced paw edema formation in rats likely occur through an inhibitory action on the release or synthesis of early mediators of inflammation, such as histamine, serotonin (5-hydroxytryptamine [5-HT]), and bradykinin [18]. These mediators participate in the development of the early local inflammatory response to carrageenan. They act in vessels by inducing vasodilation and increasing vascular permeability, which are important triggers of edema formation [29, 30].

The 200-mg dose of VCO was used to investigate the possible mechanism of its anti-inflammatory effects. Rinald et al. [17] reported that a crude extract from husk fiber of $C$. nucifera decreased 
paw edema $1 \mathrm{~h}$ after a histamine injection in rats. Oral VCO administration decreased $(p<0.05)$ acute inflammation that was induced by histamine 30 min after induction, possibly through $\mathrm{H}_{1}$ receptor blockade ( $\triangleright$ Fig. $\mathbf{4 a}$ ). This mechanism of action of VCO is different from dexamethasone, which modulates histamine by attenuating mast cell degranulation [31]. Previous studies showed that histamine and mast cells do not play a primary role in BjcuV-induced paw edema. The $\mathrm{H}_{1}$ receptor antagonist loratadine and the compound 48/80 (a mast cell degranulator/depletor) did not prevent damage that was caused by BjcuV [7]. However, Landucci et al. [3] reported the significant participation of histamine, dependent from mast cell degranulation, in paw edema that was induced by 2 myotoxins (i. e., bothropstoxin-I and -II) that were isolated from BjcuV. These myotoxins have structures and activity that are similar to $\mathrm{PLA}_{2}$. The present findings regarding the anti-histaminergic effect of VCO and the possible applicability of VCO in other experimental models of diseases (e. g., allergies and asthma) require further investigation.

Similar to histamine, serotonin is preformed in cytoplasmic granules of mast cells and platelets and has proinflammatory effects. Serotonin contributes to the sensitization of nerve fibers that is observed in inflammatory processes that are induced by Bothrops snakebites [5]. Furthermore, serotonin modulates the signal that is responsible for the chemotaxis of neutrophil migration during the innate immune response [32] and by modify the vascular permeability induce paw edema by 120 min later [33].

- Fig. $\mathbf{4 b}$ shows that VCO significantly decreased $(p<0.05)$ edema that was induced by serotonin. A similar result was reported for a crude extract from husk fiber of $C$. nucifera in rats [17]. The possible mechanisms of action of VCO may involve the modulation of 5-HT receptors. 5-HT receptors have been reported to participate in paw edema that is elicited by toxins from the venom of Bothrops jararacussu, Bothrops jararaca, and Bothrops lanceolatus [3-5]. The peripheral activity of serotonin that acts at $5-\mathrm{HT}_{1}$ and $5-\mathrm{HT}_{2}$ receptors modifies vascular permeability and indirectly allows the flow of other pronociceptive and proinflammatory factors, such as bradykinin and eicosanoids [34].

Bradykinins participate in the genesis of local edema and act as important pain mediators in the pathophysiological process of Bothrops snakebite accidents [35]. In the present study, to reproduce the effects of bradykinin, the animals were first intraperitoneally pretreated with $5 \mathrm{mg} / \mathrm{kg}$ captopril $30 \mathrm{~min}$ before the injection of bradykinin to inhibit the activity of the angiotensin-converting enzyme, which is involved in the biological degradation of bradykinin and blocked by Bothrops toxins [35]. Thus, the bradykinin injection resulted in edema formation, which peaked at $10 \mathrm{~min}$ and was attenuated $(p<0.05)$ by VCO treatment ( $\vee$ Fig. $4 \mathbf{c}$ ).

The participation of bradykinin in the process of BjcuV-induced edema formation is still uncertain. Wanderley et al. [7] reported that pretreatment with the bradykinin receptor antagonist HOE140 did not prevent edema that was induced by BjcuV. Rioli et al. [6] reported the presence of a bradykinin-potentiating peptide in $\mathrm{B}$. jararacussu toxin. Such compounds increase the recruitment and adherence of leukocytes and vasodilation.

In the present study, substance $P$ induced paw edema, and this effect was not prevented by VCO pretreatment ( $p>0.05$; $>$ Fig. 4d). The desensitization of afferent $\mathrm{C}$-fibers by capsaicin did not affect the formation of edema or migration of neutrophils to the site of injury that was caused by BjcuV [7]. Thus, we speculate that substance $P$ does not participate in the inflammatory response that is induced by BjcuV. Our results indicate that VCO does not modulate substance $P$ in this experimental mouse model of inflammation.

According to Zakaria et al. [19], VCO inhibits phlogistic mediators, such as autacoids. Prostaglandins, unlike many autacoids, are not stored in vesicles or other organic compartments, and they require synthesis that depends on the enzymatic activity of $\mathrm{PLA}_{2}$ that is present in phospholipids within cell membranes. The product of this reaction is arachidonic acid, which is then acted upon by cyclooxygenase (COX), producing the final synthesis of prostaglandins. BjcuV increases the activity of $\mathrm{COX}_{2}$, and prostaglandins are major inflammatory mediators that are involved in paw edema that is induced by BjcuV in mice [7]. We further investigated the effect of VCO on inflammation that was elicited by exogenous prostaglan$\operatorname{din} E_{2}$. Pretreatment with VCO did not prevent $(p>0.05)$ edema that was triggered by prostaglandin $\mathrm{E}_{2}$ ( $\triangleright \mathbf{F i g}$. $\mathbf{4 e}$ ). We cannot exclude the possibility that the anti-inflammatory effect of VCO occurs through the attenuation of $\mathrm{COX}_{2}$ activation that is elicited by BjcuV and not through the direct blockade of prostaglandin receptors.

Notably, BjcuV stimulates the migration of neutrophils to the paw in mice [7]. In a previous study, an aqueous crude extract of $C$. nucifera inhibited the inflammatory process that was induced by a subcutaneous injection of carrageenan by reducing leukocytes and protein extravasation [21]. In the present study, carrageenan increased the number of leukocytes in the peritoneal exudate $\left(7.74 \pm 0.23 \times 10^{6}\right.$ cells $/ \mathrm{ml}$ vs. $14.23 \pm 1.85 \times 10^{6}$ cells $\left./ \mathrm{ml}\right)$, which was prevented by $200 \mathrm{mg}$ VCO $\left(6.57 \pm 0.5 \times 10^{6}\right.$ cells $\left./ \mathrm{ml}\right)$ and dexamethasone $\left(6.20 \pm 0.68 \times 10^{6}\right.$ cells $\left./ \mathrm{ml}\right)$. These results suggest that VCO exerts anti-inflammatory effects at least partially through interactions with several of these pathways that are involved in leukocyte migration. Including the VCO to neutralize reactive oxygen species (ROS) that are produced by neutrophils in the inflammatory process $[21,26]$.

Intraplantar injections of $\mathrm{B}$. jararaca venom caused hyperalgesia in rodents $[36,37]$. Crude extracts and VCO of $C$. nucifera have been reported to have antinociceptive effects in different rodent models of pain [17-21]. We investigated the possible analgesic effects of VCO on hyperalgesia that was induced by BjcuV. Virgin coconut oil at a dose of $200 \mathrm{mg}$ significantly decreased $(p<0.05)$ mechanical hypernociception that was induced by BjcuV $2 \mathrm{~h}$ after pain stimulation, and this analgesic effect persisted throughout the study. The positive control tramadol significantly decreased $(\mathrm{p}<0.05)$ mechanical hypernociception $1,2,4$, and $5 \mathrm{~h}$ after the BjcuV injection ( $\triangleright$ Fig. 5).

To elucidate the mechanism of the antinociceptive effect of VCO, the animals were pretreated with the opioid receptor antagonist naloxone. $>$ Fig. 5 shows that naloxone blunted the antinociceptive effect of VCO on BjcuV-induced mechanical hypernociception $3 \mathrm{~h}$ after the BjcuV injection. A previous study also reported that the analgesic effects of $C$. nucifera occurred through opioid receptors [17].

In summary, in the present study VCO decreased paw edema that was induced by BjcuV and inflammatory mediators, including histamine, serotonin, and bradykinin. Virgin coconut oil also inhibited leukocyte migration to the inflammatory focus and decreased BjcuV-induced mechanical hypernociception. The 


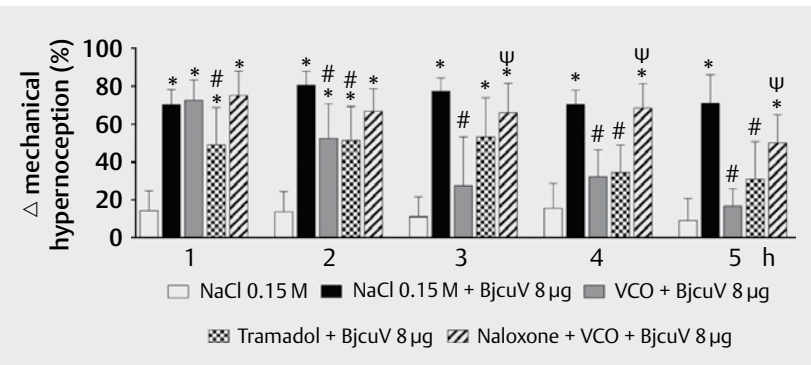

- Fig. 5 Antinociceptive effect of virgin coconut oil on BjcuV-induced mechanical hyperalgesia in mice. The data represent variations in mechanical hypernociception that was evaluated for $5 \mathrm{~h}$ in mice that were orally treated with $0.2 \mathrm{ml}$ of $0.15 \mathrm{M} \mathrm{NaCl}$ and then received an intraplantar injection of saline ( $30 \mu \mathrm{l}$, negative control) and in mice that were treated with $0.2 \mathrm{ml}$ of $0.15 \mathrm{M} \mathrm{NaCl}$ (p.o., control), virgin coconut oil (VCO; $200 \mathrm{mg}$, p.o.), or tramadol $(40 \mathrm{mg} / \mathrm{kg}$, i.p., positive control) and then received an intraplantar injection of BjcuV $(8 \mu \mathrm{g} /$ paw) 60 min later. Other animals received VCO (p.o.) and then BjcuV, followed by naloxone. The data are expressed as the mean \pm SEM from 5 animals per group. ${ }^{*} P<0.05$, vs. negative control group; ${ }^{\#}<<0.05$, vs. control group; ${ }^{\psi} p<0.05$, vs. VCO group.

antinociceptive effects of VCO appeared to occur through opioid receptors. The present results support the possible therapeutic use of coconut products, which have been used a nutraceutical products in animals and humans for the treatment of inflammatory diseases.

\section{Materials and Methods}

\section{Drugs and venom}

Virgin coconut oil (Batch no. 91026716) was purchased from Copra Sul Natural Products. It was obtained from the fruit endosperm of C. nucifera. Lyophilized BjcuV was obtained from the Butantan Institute, São Paulo, Brazil. The venom was maintained at $20^{\circ} \mathrm{C}$ and diluted in $0.9 \%$ sterile saline. Dexamethasone (Decadron ${ }^{\circledR}$, batch no. 1113428) was purchased from Aché Pharmaceutical Laboratories SA. Carrageenan, histamine, serotonin, bradykinin, substance $\mathrm{P}$, and prostaglandin $\mathrm{E}_{2}$ were purchased from Sigma. Tramadol (purity $99.7 \%$, batch no. AW 022/14) was obtained from Hipolabor. Naloxone (purity >95\%, batch no. 08129231 ) was obtained from Cristália.

\section{Nuclear magnetic resonance spectra}

${ }^{1} \mathrm{H}$ - and ${ }^{13} \mathrm{C}$-NMR spectra were acquired in $\mathrm{CDCl}_{3}$ at $301 \mathrm{~K}$ using a BrukerAVANCE III 400 NMR spectrometer that operated at 9.4 Tesla, observing ${ }^{1} \mathrm{H}$ and ${ }^{13} \mathrm{C}$ at 400 and $100 \mathrm{MHz}$, respectively. The spectrometer was equipped with a 5-mm multinuclear inverse detection probe with a z-gradient. All of the ${ }^{1} \mathrm{H}$ - and ${ }^{13} \mathrm{C}$-NMR chemical shifts are presented in ppm and were related to the TMS signal at $0.00 \mathrm{ppm}$ as an internal reference. The coupling constants (J) are presented in $\mathrm{Hz}$.

\section{Animals}

Female Swiss mice ( $\mathrm{n}=125 ; 25-30 \mathrm{~g}$ body weight) were housed at a temperature of $25^{\circ} \mathrm{C} \pm 2{ }^{\circ} \mathrm{C}$ under a $12 \mathrm{~h} / 12 \mathrm{~h}$ light/dark cycle (lights on at 6:00 AM) with food and water available ad libitum (Pu- rina Lab). All experiments were performed in accordance with the Guide for the Care and Use of Laboratory Animals (National Institutes of Health, Bethesda, MD, USA) and were approved by the Ethics Committee in Research of the Federal University of São Francisco Valley (protocol no. 12081038).

\section{Effect of virgin coconut oil on paw edema induced by B. jararacussu venom}

To investigate the local effects of BjcuV, the mice were divided into groups of 5 animals each. They received injections of the following in the subplantar region of the right hindpaw: $30 \mu$ of $0.15 \mathrm{M} \mathrm{NaCl}$ (control group) or BjcuV ( $8 \mu \mathrm{g} / \mathrm{paw}$ ) plus oral treatment with 100 , 200 , or $400 \mathrm{mg} V C O$ in oil solution or $0.2 \mathrm{ml}$ of $0.15 \mathrm{M} \mathrm{NaCl}$. The VCO was weighed, and respective volumes were administered by gavage $1 \mathrm{~h}$ before the injection of BjcuV. In other experimental groups, dexamethasone $(1 \mathrm{mg} / \mathrm{kg}$, positive control) was administered intraperitoneally $1 \mathrm{~h}$ before the injection of BjcuV.

Paw edema was measured by plethysmography (PanLab 7500 water plethysmometer) immediately before (basal volume) and then hourly for $5 \mathrm{~h}$ after the BjcuV or saline injection. The results are expressed as the difference between the final and basal paw volumes (\% variation of paw volume) [38].

\section{Effect of virgin coconut oil on paw edema induced by different phlogistic agents}

To investigate the possible mechanisms that are involved in the anti-inflammatory activity of VCO, additional groups of 5 animals each were orally pretreated with $0.2 \mathrm{ml}$ of $0.15 \mathrm{M} \mathrm{NaCl}$ (control) or $200 \mathrm{mg}$ VCO. One hour after pretreatment, paw edema was induced by an intraplantar injection of serotonin ( $300 \mathrm{ng} / \mathrm{paw})$, histamine $\left(100 \mu \mathrm{g} /\right.$ paw), prostaglandin $E_{2}(30 \mathrm{ng} /$ paw), substance $P$ (800 pg/paw), or bradykinin (320 pg/paw) in the right hindpaw [34]. Paw volume was measured immediately before (basal volume) and $30,60,90$, and 120 min after the histamine, serotonin, prostaglan$\operatorname{din} E_{2}$, and substance $P$ injections. For bradykinin, paw edema was evaluated $10,20,30,60,90$, and $120 \mathrm{~min}$ after the injection. The edema response was measure as described previously [38].

\section{Effect of virgin coconut oil on carrageenan-induced peritonitis}

To determine neutrophil migration to the peritoneal cavity, the mice were treated with $0.2 \mathrm{ml}$ of $0.15 \mathrm{M} \mathrm{NaCl}$ solution (p.o.), $200 \mathrm{mg}$ VCO (p.o.), or $1 \mathrm{mg} / \mathrm{kg}$ dexamethasone (i.p.). Each group consisted of 5 mice each. One hour later, $250 \mu$ l of carrageenan was administered ( $500 \mu \mathrm{g} /$ cavity, i.p.). The mice were euthanized $4 \mathrm{~h}$ later, and the peritoneal cavity was washed with $1.5 \mathrm{ml}$ of heparinized phosphate-buffered saline to harvest peritoneal cells. The recovered volumes were similar in all experimental groups and equivalent to $\sim 95 \%$ of the injected volume. Total cell counts were performed in a Neubauer chamber. The results are presented as the total number of leucocytes per milliliter of peritoneal exudate as previously described [39].

\section{Effect of virgin coconut oil on B. jararacussu venom- induced mechanical hypernociception}

The animals were first fasted for $18 \mathrm{~h}$ and then orally treated with $0.2 \mathrm{ml}$ of $0.15 \mathrm{M} \mathrm{NaCl}$ (p.o., negative control), $200 \mathrm{mg}$ VCO (p.o.), 
or $40 \mathrm{mg} / \mathrm{kg}$ tramadol (i.p., positive control). One hour later, they received an intraplantar injection of $30 \mu \mathrm{l}$ of $0.15 \mathrm{M} \mathrm{NaCl}$ or BjcuV $(8 \mu \mathrm{g} / \mathrm{paw})$ in the right hindpaw. Mechanical hypernociception was then assessed for $5 \mathrm{~h}$. The mechanical nociceptive threshold was assessed by stimulating the hindpaws with a pressure meter that consisted of a handheld force transducer that was fitted with a $0.5 \mathrm{~mm}^{2}$ polypropylene tip (electronic von Frey Digital Analgesymeter; Insight Instruments). In a quiet room, the mice were placed in acrylic cages $(12 \mathrm{~cm} \times 20 \mathrm{~cm} \times 17 \mathrm{~cm})$ with wire grid floors $1 \mathrm{~h}$ before the test. A tilted mirror was placed under the grid to provide a clear view of the hindpaw. The investigator was trained to apply the tip perpendicularly to the central area of the hindpaw using a gradual increase in pressure. The stimulus was discontinued and its intensity recorded when the paw was withdrawn. The end-point was characterized by removal of the paw in a clear flinch response after paw withdrawal. The difference in mechanical nociceptive thresholds before and after the BjcuV injection was calculated [40]. To assess the possible analgesic mechanism of action of VCO, the animals were treated with $1 \mathrm{mg} / \mathrm{kg}$ naloxone (i.p). $15 \mathrm{~min}$ later, they received $200 \mathrm{mg}$ VCO (p.o.) to evaluate mechanical hypernociception that was induced by BjcuV.

\section{Statistical analysis}

The data are expressed as mean \pm standard error of the mean (SEM). The data were analyzed using 2-way analysis of variance (ANOVA) followed by the Student-Newman-Keuls test, as appropriate. Values of $p<0.05$ were considered statistically significant.

\section{Acknowledgements}

We are indebted to the Butantan Institute, São Paulo, Brazil, for supplying the $B$. jararacussu venom. The present study was supported by scholarship grants from CNPq and FACEPE.

\section{Conflicts of Interest}

The authors declare that they have no conflict of interest.

\section{References}

[1] da Silva C], Jorge MT, Ribeiro LA. Epidemiology of snakebite in a central region of Brazil. Toxicon 2003; 41: 251-255

[2] Galvão Nascimento N, Sampaio MC, Amaral Olivo R, Teixeira C. Contribution of mast cells to the oedema induced by Bothrops moojeni snake venom and a pharmacological assessment of the inflammatory mediators involved. Toxicon 2010; 55: 343-352

[3] Landucci EC, Castro RC, Pereira MF, Cintra AC, Giglio JR, Marangoni S, Oliveira B, Cirino G, Antunes E, De Nucci G. Mast cell degranulation induced by two phospholipase A2 homologues: Dissociation between enzymatic and biological activities. Eur J Pharmacol 1998; 343: 257-263

[4] Gonçalves LR, Mariano M. Local haemorrhage induced by Bothrops jararaca venom: Relationship to neurogenic inflammation. Mediators Inflamm 2000; 9: 101-107

[5] Guimarães AQ, Cruz-Höfling MA, Ferreira de Araújo PM, Bon C, Lôbo de Araújo A. Pharmacological and histopathological characterization of Bothrops lanceolatus (Fer de lance) venom-induced edema. Inflamm Res 2004; 53: 284-291
[6] Rioli V, Prezoto BC, Konno K, Melo RL, Klitzke CF, Ferro ES, FerreiraLopes M, Camargo AC, Portaro FC. A novel bradykinin potentiating peptide isolated from Bothrops jararacussu venom using catalytically inactive oligopeptidase EP24.15. FEBS J 2008; 275: 2442-2454

[7] Wanderley CWS, Silva CM, Wong DV, Ximenes RM, Morelo DF, Cosker F, Aragão KS, Fernandes C, Palheta-Júnior RC, Havt A, Brito GA, Cunha FQ, Ribeiro RA, Lima-Júnior RC. Bothrops jararacussu snake venominduces a local inflammatory response in a prostanoid- and neutrophildependent manner. Toxicon 2014; 90: 134-147

[8] da Silva IM, Tavares AM. Comparative evaluation of adverse effects in the use of powder trivalent antivenom and liquid antivenoms in Bothrops snake bites. Rev Soc Bras Med Trop 2012; 45: 523-525

[9] Armentano RA, Schaer M. Overview and controversies in the medical management of pit viper envenomation in the dog. J Vet Emerg Crit Care 2011; 21: 461-470

[10] Simon JP, Prince SE. Natural remedies for non-steroidal anti-inflammatory drug-induced toxicity. J Appl Toxicol 2017; 37: 71-83

[11] da Silva GA, Domingos TF, Fonseca RR, Sanchez EF, Teixeira VL, Fuly AL. The red seaweed Plocamium brasiliense shows anti-snake venom toxic effects. J Venom Anim Toxins Incl Trop Dis 2015; 21: 2

[12] Magalhães A, Santos GB, Verdam MC, Fraporti L, Malheiro A, Lima ES, Dos-Santos MC. Inhibition of the inflammatory and coagulant action of Bothrops atrox venom by the plant species Marsypianthes chamaedrys. J Ethnopharmacol 2011; 134: 82-88

[13] Félix-Silva J, Souza T, Menezes YA, Cabral B, Câmara RB, Silva-Junior AA, Rocha HA, Rebecchi IM, Zucolotto SM, Fernandes-Pedrosa MF. Aqueous leaf extract of Jatropha gossypiifolia L. (Euphorbiaceae) inhibits enzymatic and biological actions of Bothrops jararaca snake venom. PLoS One 2014; 9: e104952

[14] Lima EBC, Sousa CNS, Meneses LN, Ximenes NC, Santos Júnior MA, Vasconcelos GS, Lima NBC, Patrocínio MCA, Macedo D, Vasconcelos SMM. Cocos nucifera (L.) (Arecaceae): A phytochemical and pharmacological review. Braz J Med Biol Res 2015; 48: 953-964

[15] DebMandal M, Mandal S. Coconut (Cocos nucifera L.: Arecaceae): in health promotion and disease prevention. Asian Pac J Trop Med 2011; 4: $241-247$

[16] Zakaria ZA, Reezal I, Mat Jais AM, Somchit MN, Sulaiman MR, Marmin AHI, Sidek H, Husin SH, Rahim MHA, Abdul Rahman L. The anti-inflammatory, anti-pyretic and wound healing activities of Cocos nucifera (MATAG types) fresh juice and kernel extracts in experimental animals. J. Pharmacol Toxicol 2006; 1: 516-526

[17] Rinaldi S, Silva DO, Bello F, Alviano CS, Alviano DS, Matheus ME, Fernandes PD. Characterization of the antinociceptive and anti-inflammatory activities from Cocos nucifera L. (Palmae). J Ethnopharmacol 2009; 122: 541-546

[18] Intahphuak S, Khonsung P, Panthong A. Anti-inflammatory, analgesic, and antipyretic activities of virgin coconut oil. Pharm Biol 2010; 48: 151-157

[19] Zakaria ZA, Somchit MN, Mat Jais AM, Teh LK, Salleh MZ, Long K. In vivo antinociceptive and anti-inflammatory activities of dried and fermented processed virgin coconut oil. Med Princ Pract 2011; 20: 231-236

[20] Naskar S, Mazumder UK, Pramanik G, Saha P, Haldar PK, Gupta M. Evaluation of antinociceptive and anti-inflammatory activity of hydromethanol extract of Cocos nucifera L. Inflammopharmacology 2013; 21: 31-35

[21] Silva RR, Oiveira e Silva D, Fontes HR, Alviano CS, Fernandes PD, Alviano DS. Anti-inflammatory, antioxidant, and antimicrobial activities of Cocos nucifera var. typical. BMC Complement Altern Med 2013; 13: 107

[22] Nneli RO, Woyike OA. Antiulcerogenic effects of coconut (Cocos nucifera) extract in rats. Phytother Res 2008; 22: 970-972 
[23] Chioma AA, Obidoa O. Anti-inflammatory and anti-ulcerogenic effect of ethanol extract of coconut (Cocos nucifera) on experimental rats. Afr J Food Agriculture Nutr Dev 2010; 10: 10-16

[24] Chioma AA, Obidoa O, Fredrick NOC, Parker E]. Anti-ulcerogenic and membrane stabilization effect of ethanol extract of coconut (Cocos nucifera). Res J Pharmacognosy Phytochem 2010; 2: 85-88

[25] Gunstone FD. Information on the composition of fats from their high-resolution ${ }^{13} \mathrm{C}$ nuclear magnetic resonance spectra. J Am Oil Chem Soc 1993; 70: 361-366

[26] Zakaria ZA, Ahmad Z, Somchit MN, Arifah AK, Khairi HM, Sulaiman MR, Teh LK, Salleh MZ, Long K. Antihypercholesterolemia property and fatty acid composition of MARDI-produced virgin coconut oils. Afr J Pharm Pharmacol 2010; 4: 636-644

[27] Barbosa AM, do Amaral RO, Teixeira CF, Hyslop S, Cogo JC. Pharmacological characterization of mouse hind paw oedema induced by Bothrops insularis (jararaca ilhoa) snake venom. Toxicon 2003; 5 : 515-523

[28] Patrão-Neto FC, Tomaz MA, Strauch MA, Monteiro-Machado M, Rocha JR Jr, Borges PA, Calil-Elias S, Melo PA. Dexamethasone antagonizes the in vivo myotoxic and inflammatory effects of Bothrops venoms. Toxicon 2013; 69: 55-64

[29] Stochla K, Maśliński S. Carrageenan-induced oedema in the rat paw: histamine participation. Agents Actions 1982; 12: 201-202

[30] Kim S, Liu M, Simchon S, Dörscher-Kim JE. Effects of selected inflammatory mediators on blood flow and vascular permeability in the dental pulp. Proc Finn Dent Soc 1992; 88 (Suppl 1): 387-392

[31] Rasanen T. Effects of dexamethasone, prednisolone and cortisol on the mast cells and tissue eosinophils in rat gastric mucosa. Acta Endocrinol (Copenh) 1962; 41: 432-436
[32] Duerschmied D, Suidan GL, Demers M, Herr N, Carbo C, Brill A, Cifuni SM, Mauler M, Cicko S, Bader M, Idzko M, Bode C, Wagner DD. Platelet serotonin promotes the recruitment of neutrophils to sites of acute inflammation in mice. Blood 2013; 121: 1008-1015

[33] Damasceno SR, Oliveira FR, Carvalho NS, Brito CF, Silva IS, Sousa FB, Silva RO, Sousa DP, Barbosa AL, Freitas RM, Medeiros JV. Carvacryl acetate, a derivative of carvacrol, reduces nociceptive and inflammatory response in mice. Life Sci 2014; 94: 58-66

[34] Pierce PA, Xie GX, Peroutka SJ, Green PG, Levine JD. 5-hydroxytryptamine-induced synovial plasma extravasation is mediated via 5-hydroxytryptamine $2 \mathrm{~A}$ receptors on sympathetic efferent terminals. J Pharmacol Exp Ther 1995; 275: 502-508

[35] Ferreira SH. History of the development of inhibitors of angiotensin I conversion. Drugs 1985; 30 (Suppl 1): 1-5

[36] Chacur M, Picolo G, Teixeira CF, Cury Y. Bradykinin is involved in hyperalgesia induced by Bothrops jararaca venom. Toxicon 2002; 40: 1047-1051

[37] Martinov T, Mack M, Sykes A, Chatterjea D. Measuring changes in tactile sensitivity in the hind paw of mice using an electronic von Frey apparatus. J Vis Exp 2013; 82: e51212

[38] Fereidoni M, Ahmadiani A, Semnanian S, Javan M. An accurate and simple method for measurement of paw edema. J Pharmacol Toxicol Methods 2000; 43: 11-14

[39] DeSimone JM, Meguid MM, Kurzer M, Westervelt J. Indomethacin decreases carrageenan-induced peritoneal adhesions. Surgery 1988; 104: 788-795

[40] Cunha TM, Verri WA Jr, Vivancos GG, Moreira IF, Reis S, Parada CA, Cunha FQ, Ferreira SH. An electronic pressure-meter nociception paw test for mice. Braz J Med Biol Res 2004; 37: 401-407 